Doi: $10.24234 / \mathrm{se} .2020 .2 .2 .233$

\title{
PARENTS VIEW ON IN-HOME OCCUPATIONAL THERAPY SERVICE
}

\author{
AUTHOR'S DATA: \\ Lilia Osipova, OT MA \\ Private Occupational Therapist, Armenia \\ Contacts: osipovaliliya-9@aspu.am
}

\begin{abstract}
Home is a significant environment for any child with or without special needs and one of the important environments where occupational therapy is aimed to bring improvement if necessary in terms of quality of life. The current descriptive qualitative study was designed to find out parental perceptions about occupational therapies provided in their own environments with their children with special needs.
\end{abstract}

The participants of the study were five parents whose children with different special needs were getting private in-house occupational therapy services provided by the researcher at the moment of the study. The data for this study was collected through semi-structured interviews. Interviews were designed to understand how parents perceive in-house Occupational Therapy Services.

The findings of the study suggest significant improvements in the quality of life of their children with special needs, thus no one could specifically differ occupational therapy interventions in-home and in other professional settings. It is obvious because of the lack of settings in Armenia with Occupational Therapies and lack of information about the profession in general. Future research is recommended to be conducted between two different groups with Occupational Therapies in-home and other settings, with a larger group and more specific issues. Findings revealed that in-home services are convenient in many different aspects for parents of children with special needs and it should be considered for future practices. 
Keywords: Occupational therapy, in-house service, parents, children with special needs, early intervention, interview.

\section{INTRODUCTION}

Unfortunately, special needs are a growing problem all over the world as well as in Armenia. Subsequently, the need for rehabilitative services is growing. There are different possibilities of services in Armenia including private in-home services, which are provided by different professionals including Occupational Therapists. In this quite young field of rehabilitation in Armenia Occupational Therapy is still developing and there is a need for further exploration and research.

Each family, in general, is unique and has its own experience, families with children with special needs differ even more. The impact of disability is shaping parents and their life perceptions in a lot of ways. As there is a lack of information, it is important to discover, describe, and interpret each experience in order to build knowledge of parental issues concerning Occupational Therapy in Armenia.

The Occupational Therapist, the author of this thesis works only in the field of pediatrics at children's homes. During the years of providing exclusively in-home service, it was noticed that time spent with parents after therapies on the list equals to half of the therapy sessions itself, on some occasions even exceeding it. Usually, parents have a lot of questions, concerns, issues connected with children, they would like to discuss or be informed about. Hence, the question about the benefits of in-home Occupational Therapy services arose.

The primary environment for children is their homes and families where they spend the majority of their time. This study was designed to investigate the view on Occupational Therapy at home through parents' perception. 


\section{LITERATURE REVIEW}

According to the Statistical Committee of the Republic of Armenia, there are 7525 registered children with disabilities in Armenia (Armstat, 2018). According to the Law of the Republic of Armenia, all disabled people have access to free health and rehabilitation care including children with disabilities (Law of social protection of persons with disabilities of RA, 1993). It includes treatment in hospitals and outpatient facilities that are operating in governmental order. However, there are two ways to get rehabilitation services in Armenia. According to disability policy, the first option is free in some rehabilitation centers that are working within the governmental order once or twice a year according to a disability type, physical or mental. The second option includes paid services at the same centers. Unfortunately, today the first option is very restricted because of very limited numbers of rehabilitation centers in Armenia. Very often, children need to register and be on the waiting list for several months or even years and then receive a restricted number of rehabilitation therapies enlisted in the government policies of free treatments. The waiting time has its negative impact on a child's development as early and intensive rehabilitation can decrease the number of disabilities and help children grow independently enabling their participation in daily life activities. According to Stephens and Tauber (2001) "early intervention refers to the most critical period of a child's development between birth and three years of age. Intervention refers to program implementation designed to maintain or enhance the child's development in natural environments and as a member of a family" (Stephens \& Tauber, 2001 p. 708). Numerous studies have identified the importance of early intervention and various benefits have been reported (Farel, Meyer, Hicken \& Edmonds, 2003; Guralnick 1997; Ayres 1979).

Despite the understanding of the importance of early intervention in Armenia as in a lot of other countries, there is significant shortness of rehabilitation services. According to UNICEF's mapping project (2017-18), there are about 30 rehabilitation centers and non-governmental organizations for disabled children all over Armenia. The majority of these centers are located in Yerevan - the capital of Armenia. They can be divided into three categories. The first category includes centers that are working dominantly within the governmental order. The oldest and biggest of them are Child Republican Rehabilitation Center and ArBeS Day Care Center which are providing both free and paid services. They are the largest facilities giving treatment to all 
kinds of disabled children either physically or mentally, with multidisciplinary teams and a large number of therapists. The second category includes big and small centers that are working within international funds or as non-governmental organizations with grants or private donations, such as "My Way" NGO, "Hay Mayrer" NGO, "Luse" NGO, etc. The diversity of therapies and the number of therapists depend on the size of the center and finances. Their services are mostly free but some of them also provide paid treatments. The third group includes small private centers run by professionals that only offer paid treatments and have limited options for treatments and professional staff.

The biggest rehabilitation center in Armenia is the Child Republican Rehabilitation Center and it yearly serves 800 children with different disabilities. ArBeS Day Care Center treats around 500 children with both physical and mental disabilities. All other centers accept a much smaller number of children from 20 in private centers to 300-400 in well-developed NGO centers such as "My Way" or "Luse". All those services are done in both unpaid and paid ways. As discussed in the aforementioned paragraph, it's obvious that there are long waiting lists in each center regardless of its size and working style. Because of that problem some centers limited their service to children below 7 years old, others accepted the same child once a year, some shortened the number of treatments one can obtain in the center. These all are done to allow a larger number of disabled children to get rehabilitation. However, the problem remains of a current interest as child rehabilitation and early intervention programs that combine a child and parent focus are reported to have a greater impact on the developmental outcomes of the child (Lekskulchai \& Cole 2001). Children are considered eligible for early intervention services if they are delayed in one or more

of the following areas: physical, cognitive, language and speech, psychosocial and self-help, or if they have a diagnosis of a physical or mental condition which will result in a developmental delay (Pelchat, Lefebvre, Proulx \& Reidy, 2004).

\section{In-home rehabilitation}

The paradigm-change in health-care started in the mid-1980s in the Western world. It shifted from health-centered care to family-centered care, so the aim of treatment shifted from illness curing onto patients' experiences with illnesses and/or disabilities (MacKean, Thurston \& Scott, 2005). Child health-care embraced that change especially because of the increase in the 
number of children with chronic illnesses and disabilities. A family-centered approach considers the client, the child patient, and their family, rather than just the patient (MacKean, Thurston, Scott \& 2005). That shift led to changes in the medical services as well as in parents' view on the health -care their children get. In this model, family is seen as a central and crucial part of a child's life. It is seen as a primary and strong source of support to overcome or fight health issues. The familycentered model points to the uniqueness of children and families and the existing diversity of people, their values, and their cultural beliefs. The family-centered model acknowledges parental expertise on a child's and family's life and their knowledge of the strengths and needs of children and family as a system. It is more competence enhancing rather than weakness focused (MacKean, Thurston \& Scott, 2005) that help to overcome impairments in the way of achieving outcomes that reflect clients' enhanced capacity to participate in their communities (MacKean, Thurston \& Scott, 2005).

Occupational therapy is a client-centered practice and it is expected to embrace the ideals of the family-centered approach, although enacting these ideals can be challenging (Graham, Rodger \& Ziviani, 2013). Thus, a successful intervention requires sensitivity to the perspectives of families (Cohn, Miller \& Tickle-Degnen, 1999). Occupational Therapists need to focus on the outcomes outlined by parents as they are front liners living with children 24/7. The impact of the life-long disability on the whole family's life and routine should be also considered. Attention should be paid to the surroundingu of the therapies within the means of family members and their expectations and not only to the process of intervention through action and gaining of performance components needed for it. Interventions with children with special needs can be effective only when they are sustainably integrated into routines of the family (Gallimore et al, 1989). Parental expectations from therapies are laying in contexts where their children live, learn, and play (Cohn et al, 1999). It is known that raising the child with a special need has a profound impact on the family system, including maternal mental health (Hauser-Cram, 2001), family routine (Marquenie, 2011), and financial status (Emerson, 2003). It is hard to overrate the need to expand Occupational Therapy intervention to a large circle of the whole family and its routine rather than provide direct sessions to the child. It should be aimed toward inclusion of parents as well as involve them in decision making, goal setting, and outcomes evaluation processes. Some will argue that parents are not experts in Occupational Therapy and will be right, but mutual work with a therapist who can enlighten a child's needs and limitations will bring to more fruitful results. Due to collaborative 
work, parents can be trained to better care, child routine management, and advocacy. Mutual goal attainment can lead to an increase in parental understanding of child's independence in everyday life. Shared responsibilities for goal achievements usually bring more insight into the therapist's work and serve to implement changes into a child's as well as a family's life. The results of different research show that the parents who want to work collaboratively with health-care providers, care about their child, make decisions and implement a dynamic care plan proved to record the best results for their children and family (MacKean, Thurston \& Scott, 2005).

The abovementioned shifting on health-care provision from health-centeredness to family -centeredness leads to a shift in care provision from professional facilities to consumers' homes. Because the model places the needs of the child and its family in the center of care in comparison that paradigm shift is further ahead in child health-care (MacKean, Thurston \& Scott, 2005). That process in child-care started even in the 1980s (Hinojosa, Anderson \& Strauch, 1998; Hinojosa, Kramer \& Royeen, 2017) and in-home child rehabilitation treatment was growing in all areas because both home environment, as well as early intervention, are considered to be a critical variable in the effectiveness of treatment (Hinojosa, Anderson \& Strauch, 1998). Home treatment can be referred to in different fields of rehabilitation such as Occupational Therapy, Physical Therapy, Speech and Language pathologist, educators, etc. Referral reasons vary on the needs of a child as well as families. Some families have difficulties using center programs but are open to accepting in-home treatment for children. Some parents have difficulties accepting that their child needs intervention especially in a medical setting, but they are open to home visits, and even over time they can recognize the need for continuing rehabilitation and get to use clinic services (Cohn, 2000). Parents can avoid centers due to transportation difficulties because clinics could be in a far distance from home. Also, if a child uses complex technical support, for example, a breathing machine or complicated wheel-chair, etc. it can be a reason for parents' unwillingness to take their child to the clinic. Parents' concerns about a child's safety in terms of health conditions such as catching flu or viruses are also one of the reasons to avoid centers. Employment and familial responsibilities such as taking care of others in the family can be an obstacle for visiting centers. Parents can prefer home treatment because of convenience (Hinojosa, Anderson \& Strauch, 1998). 


\section{In-home rehabilitation in Armenia}

In many countries of the western world (The Netherlands, Austria, Belgium, Germany) home-based rehabilitation treatment is well developed now and includes in it an early intervention. Children with special needs get their treatment at home for several years depending on the country and its disability policy. However, in Armenia, the situation with in-home treatment is a bit different. Armenians ethnically and culturally are a child-centered society in terms of adoring, spoiling, nourishing their children. It's especially exaggerated with the first-borns. Nowadays the quantity of children in Armenian families is decreased as well as in all civil world, there are 1-3 children in families. There are different reasons for that but most people mention the economical reason as the primary one.

Even though rehabilitation is a quite young discipline in Armenia, it started in the early '90s after a devastating earthquake in 1988 in Spitak, there always were limitations to get rehabilitation because of the abovementioned shortness of facilities as well as access to free treatment. Because of those limitations, in-home rehabilitation practice had started to develop in Armenia. It is started with Physical Therapy as at that period it was the only rehabilitative profession practiced in adult and child treatment in newly opened rehab centers. Then other related professionals such as Speech Therapists and later Occupational Therapists (OT) got involved due to their development in the field. Occupational Therapy started in Armenia in the 2000s when inhome treatment practice was well developed in its values and curricula. Even being students, Occupational Therapists used to do home visits to clients and have some interventions there. But it had occasional and learning character in the first years of development of the profession in Armenia. Several years ago, when the profession become more or less known in the rehabilitation world of Armenia OT's started to work in in-home rehabilitation with children with different types of disabilities.

The demand for having in-home rehabilitation treatment emerged from parents of children with special needs as they understood the need for early intervention, intensity, and permanency of therapies. It became obvious that during the pause in between treatment rounds in centers by a governmental order, children lose some skills and abilities due to different reasons such as an absence of professional control, laziness of child or care-takers, pity towards the child, or natural child growth, etc. So, care-takers started to seek for professionals who will provide therapies at 
their homes. Even all abovementioned referral reasons such as difficulties using centers programs, acceptance of their child's need of intervention, transportation difficulties, child's safety in terms of health conditions are true for Armenia as well, but mostly referral reason is long waiting time for institutional services and parents prefer to get to private services. In comparison with the western world in Armenia, the biggest restriction in in-home services is payment. In-home services in Armenia are paid by parents, because there are no agencies in Armenia, such as governmental or insurance companies who will pay professionals who provide in-home rehabilitation. This situation leads to the restriction of getting in-home treatment for the majority but the financially able ones. Even so, it doesn't diminish the need to investigate parents' attitudes toward Occupational Therapy in different settings.

The aim of this research is to find out parental perception on having Occupational Therapy treatment with their children particularly the in-home environment. Based on the study the research question is: are there benefits of having Occupational Therapy in-home, not at the centers?

\section{METHOD}

To understand the parent's perception of having Occupational Therapy services provided in their homes in this study qualitative research frame was used. Since "qualitative research is about authentic engagement with the context within which one is situated, to advance understanding in the topic of interest" (Nayar \& Stanly, 2016). Specifically, a descriptive qualitative approach was used because it gives the possibility to "seek the view or perspective of a sample group" (Nayar \& Stanly, 2016), and help to describe a phenomenon in details and different aspects of the phenomenon can be recorded. This approach is useful in particular for evaluating participants' views on services or topics, findings can be used to improve the quality of services. Qualitative descriptive research results are easily conveyed to other professionals or clients without the need of knowing the theoretical orientation (Nayar \& Stanly, 2016). Houses of the children with special needs served as substantive settings for this research. Semi-structured indepth interviews were conducted with participants to assess their perceptions about in-home Occupational Therapy services. 


\section{Participants}

The target population was the parents with children with special needs, regardless of specificity. Choosing criteria for participation were:

a) currently having an in-home Occupational Therapy service,

b) in-home service must be provided at least for six months. Gender, age, and relation to the child were not relevant but the person should be a primary caretaker and decision-maker for a child.

All participants were the clients of the researcher. They were informed about the aim of the study and informed consent was confirmed. All participants were from middle to higheconomical home environment. Detailed data about the participants are represented in Table 1.

Five primary caretakers of children with special needs were chosen to be the participants of current research.

\section{Table 1.}

Participants of the study

\begin{tabular}{|l|l|l|l|l|l|l|}
\hline & Age & Gender & Education & $\begin{array}{l}\text { Relation to } \\
\text { the child }\end{array}$ & $\begin{array}{l}\text { Child's } \\
\text { age }\end{array}$ & Diagnosis of children \\
\hline Participant 1 & 34 & female & University & Mother & 6 & $\begin{array}{l}\text { Dysgenesis of corpus } \\
\text { colosseum }\end{array}$ \\
\hline Participant 2 & 70 & female & School & Grandmother & 7 & Autism \\
\hline Participant 3 & 45 & female & University & Mother & 15 & Cerebral Palsy \\
\hline Participant 4 & 32 & female & University & Mother & 7 & Cerebral Palsy \\
\hline Participant 5 & 28 & female & University & Mother & 2 & Williams Syndrome \\
\hline
\end{tabular}

\section{Ethical considerations}

Since there was no research ethics committee in Armenia, gaining an official ethical license for the research was not possible. The research plan was approved and verified with the research 
supervisors at first; secondly, permission was gained from the parents and caregivers of the children. Additionally, participants were given the written information on the research aim, their rights, and the ethical obligations of the researcher. Also, informed consent was introduced to the participants. The names of the participants were kept anonymous and not used in the study.

\section{Data collection}

A semi-structured interview was designed for the data collection within the frame of this study (Adams, 2010; 2015). Semi-structured in-depth interviews often used by professionals, Occupational Therapists were included to get knowledge about the client's condition and complaints. During the in-depth semi-structured interviews “open, direct, verbal questions are used to elicit detailed narratives and stories" (Whiting, 2008). This kind of interviewing is used in a situation where a little is known about the topic of interest. It is one of the best tools to dig deeper. The semi-structured interviews are conducted conversationally and are the combination of closedand open-ended questions, accompanied by why or how questions that lead to getting more variabilities of answers (Adams, 2010; 2015). A questionnaire with 4 questions containing subquestions was designed to collect data about parents' perception of the topic.

\section{Data analysis}

Thematic analysis method was used to analyze the collected data. This method helps to search, analyze, identify, and report themes within data (Braun \& Clarke, 2006). The thematic analysis is a search for themes that emerge as being important to the description of the phenomenon (Daly, Kellehear \& Gliksman, 1997). The process involved the identification of themes through "careful reading and re-reading of the data" (Rice \& Ezzy, 1999, p.258)

All interviews were recorded and transcribed verbatim to produce the data. Emerged themes were taken out using the transcripts from all interviews. When interviews were analyzed, themes emerged regarding parents' perceptions about Occupational Therapy in-home services and special needs as a whole. Themes were outlined if two or more parents stated similar concerns, thoughts, responses, or opinions. Supporting quotes were identified and documented during the data analysis. 


\section{RESULTS}

The results of the study were derived from the interviews and four themes were developed from the analysis of the data. The citations to the themes were presented to prove the reliability and validity of the developed themes.

\section{Tragic perception of "disability"}

While reflecting this theme, caretakers mentioned that it was "quite a shock to know about that, and standard questions came "why me, what for the end so on", "immediate hopelessness, but still deep inside there was still some little hope”, “when I knew about that I didn't deeply understand what is it, later when I explored it... surely it was shocking" (Participant 2). Generally, people all over the world as well as Armenians expect their children to be born "normal". Under the term "normal" they mean healthy and "ordinary, not different". Three of the children were diagnosed long after they were born, at the age of one, three, and even 12 years. Two others have been reported of some problems just after they have been born, which were proved with following medical examinations. Family life is drastically changing when a child is born or gets at some point in its life a disability. Usually, a disability strikes the lives of people out of the blue. One of those mentioned "even though, we were informed at the hospital about the child's condition and monthly check-up, understanding of the problem came later, when she couldn't sit herself, then we started to worry" (Participant 4). But even so, all parents mention that at some point they came to the decision making of "what to do?". Acceptance of having a "problem" with their child is quite a difficult process for all parents. Some of them don't accept it for the rest of their lives, they can cope with it, live with it, struggle even work toward overcoming it but still never accept it. Some never understand that there is a problem, they neglect it and prefer to blame the child, people around, family members, mostly mothers in spoiling the child, and fulfilling all the wishes. At that point, they all mentioned that it is not like a shock, as well as tragic perception is gone, but the necessity to help the child is becoming more important. So, they mentioned that "All your questions vanish when you put them up and understand that you have to make a normal life for this child", "you just get over yourself and accept that there is no other choice", "That little hope inside pushes you to act, to do something for him”, "you want to accept what you have” (Participant 5). However, one mother mentioned that "I am still not putting it up, even after all these years" (Participant 2) whose child is already 15 years old. 


\section{$\underline{\text { Early intervention }}$}

The first basic theme outlined by all participants was the possibility of early intervention. That was a crucial part of getting in-home services for Armenian parents. After accepting the fact their child is different as well as other related information, parents learned that treatment could be in different ways free of charge in some rehabilitation centers, paid in the same ones or others and private at home. But they need to have it as soon as possible because every minute is important. "It was difficult to find the right place and the right specialist, there are limited rehabilitation centers in the city, almost every center is overloaded, and we need to wait in the queue, but can the child wait, no he loses every day, in this sense in-home service was the only alternative..." (Participant 1). So the treatments in centers are delayed due to the lack of the centers and a large number of children. None of the parents wanted to waste time anymore so they started to explore possibilities. Finally, through private contacts, all of the responders found the possibility to get inhome services provided by Physical or Occupational Therapists privately.

\section{Personal convenience to have in-home service}

Shock coping periods and measures are different to all people. It depends on personal characteristics and social networks around. Some coping aids in the current research were mentioned as "my family", meaning in one case the current family of husband and in-laws, in another case their own parents. One mother said, "I don't know how convenient it will be here but my faith helped me to deal with this problem". Wish to do "all of possible to help my daughter to get her a good life...yeah a normal life" (Participant 3). Wish to "Make his sisters' future life easier, because they will take care of him in the future”. At the moment of interviewing all responders mentioned that rehabilitative works positive results help to keep hope.

As it is mentioned above at some point, all parents concluded that the child needs some help. These conclusions were driven by different reasons. Some mentioned that the child was "physically delayed in comparison with my niece who is the same age as her", "when I compare her with others on the playground it was discomforting". One mother mentioned that "searching for any help was like hanging on straws for me, another way to keep hope" (Participant 2). Those who used the Internet started to search for information about a child's disability and where to refer for help. Others started to ask friends and relatives here and there to get to someone with similar 
problems. Mostly, in the end, all found some doctors or hospitals where they were given some information about treatments their children should get. Two out of five recipients in referral got a clear reference to get Occupational Therapy, that referrals were from medical doctors, one from Germany, one from Armenia. Two were referred by a Physical therapist who worked with those children, and one through another child's parents who already got Occupational therapy. Among other information parents learned that treatment could be in different ways free of charge in some rehabilitation centers, paid in the same ones or others and private at home. As it is mentioned above treatments in centers are delayed due to the lack of centers and a large number of children. None of the parents wanted to waste time anymore so they started to explore possibilities. Finally, through private contacts, all of the responders found the possibility to get in-home services provided by Physical or Occupational therapists privately.

Although all parents were given clear names of therapy they have to take, Occupational Therapy, among others, none of them had any understanding of what it is, why it is, and some of them where to get it. Even some of them were directed by doctors, others searched on the Internet, none of them knew what Occupational therapy is, and which are the benefits of it for their children. "I did not know at all until you came to us and explained", "I got some idea from the Internet, but you made it more or less clear when came to us", "we didn't know but our friend told us that it's what our child needs", "physical therapist tried to explain why we need it" (Participant 4).

All parents found current Occupational Therapists through personal acquaintance of therapists with referees. Trusting the professionals who advised the parents to get in contact with the current researcher. One of the reasons to contact the therapist was that therapies will be provided at home. During the research, it became clear that convenience is the strongest reason for getting in-home therapy. Parents mentioned that for them it is "convenient, you know time-saving for me, I am at home, no rush and running", "give heaps of time to converse with a therapist about my child, before and after session, ask questions about her development", "comfortable for me, I am not worried where the child is what he is doing, how they get the therapy because he would come with grandmother in that case", "I can't get out from home because of my physical condition, so it is very helpful that you come to us, and I can see at any moment what you are doing" (Participant 3). For children parents mentioned that "You know long distance is hard for her and getting into the car and back, all this is tiring for her", "she is more concentrated at home because 
there is no noise and cries of other children and therapists around", "less disturbing environment, because it's her home and she is used to it", "for my daughter is easy to learn something, to focus, to get acquainted in a known environment because she is very curious and eager to explore and look all around in other places" (Participant 2). One of the parents has noticed that "it is safe for him, no need to get out .... how to tell...it is not convenient and useful" (Participant 5). Another response reflects another point: "I am afraid that she will copy wrong attitudes from other children because she is quick to do that, at least I was at that time...so it is good that it is at home" (Participant 2). One mentioned "Do you remember she had then big difficulties with traveling in a car, she couldn't sit or lie still and she panicked in the car, we rarely took her anywhere, it was a bliss to have therapies at home" (Participant 3). All parents in different words noticed that "you know home is home, it is cozier and Ifeel more secure for her/him " (Participant 1, 2, 3, 4, 5).

\section{Occupational Therapy in-home benefits exist}

All responders' children were getting Occupational Therapy for a long period, from one year to three. But mostly they couldn't specify the difference between in-home and center services. All mentioned that their child has learned a lot of everyday life skills and that it makes their lives easier. "Now he can go for shopping, yeah... with a list of goods and how much he will spend but at least alone, even cross the road watching to traffic lights" (Participant 1), "he can use certain numbers of mini buses to come home from school and go to "Tumo center" by himself" (Participant 2), "he uses the toilet, we don't use deeper anymore, he goes himself, switches on the lights, puts off the clothes and pees, then flushes the water and washes his hands" (Participant 4), "you know she started to notice with voice and shows with hand that she needs the toilet" (Participant 5), "she is writing, drawing, cutting, you know children with Cerebral Palsy like her mostly can't" (Participant 3). There are even more things their children can do now parents couldn't differ whether it is due to the benefits from in-home Occupational Therapy service or Occupational Therapy itself. As parents said "oh, you puzzled me... I have nothing to compare, we never get Occupational Therapy anywhere but at home", "I don't know if they can do in the center what you do at home", "there are no Occupational Therapists in the center we go for Physical therapy" (Participant 2). 


\section{DISCUSSION}

The results of this study provided an insightful understanding of the perceptions of the parents whose children have in-home Occupational Therapy services. The results of this study showed that the perception of disability striking out of the blue in Armenian parents does not differ from others all over the world. And that profound impact on the wider family system in terms of maternal mental health (Hauser-Cram, 2001), family routine (Marquenie, 2011), and financial status (Emerson, 2003) are common for Armenia as well. Coping mechanisms are developed during the time of processing "tragedy" but the impact is lifelong lasting.

Based on the results of this study, the strongest reason to get an in-home Occupational therapy is the convenience. Hinojosa, Anderson, and Strauch (1988) stated that as one of the reasons for home treatment. All of the parents mentioned that as the main reason for having therapies at home. In a broad term of convenience, various difficulties were outlined such as long waiting lists in governmental facilities, long distances to centers, mobility difficulties of child, safety issues for health conditions. All those are well-known reasons for in-home child rehabilitation care. However, all abovementioned have a personal character.

Parents in this study did not mention having an Occupational Therapy at home as their first choice. All mentioned that decision was made out of lack of the services at centers and in no other choice in private practices. Moreover, none of them was familiar or informed about the existence of such type of therapy and its field of interest. Other practitioners, such as doctors and physical therapists, and service consumers' familiarity with the special needs field played a crucial role in service seeking. Being educated in rehabilitation care or getting it, they could recognize the need for and refer to Occupational Therapy. Three out of five parents did an additional web search for further information about therapy and its probable benefits. That gave some insight but very a broad and vague understanding. All participants mentioned that they grasped the meaning of Occupational Therapy during the time of getting service little by little.

Complimentary to the family-centered approach, all participants mentioned home and family environment during the therapies as one of the most positive sides of in-home treatment. That is echoing with paradigm-shifting from health-centered to family-centered (MacKean, 
Thurston \& Scott, 2005). All parents pointed out that they could be a part of therapies and decision making.

However, the benefits of Occupational Therapies during in-home treatment weren't specified because all of the participants' children didn't get Occupational Therapy in other places such as centers. The progress in children's development in areas specific to Occupational Therapy such as different activities of daily living, grooming, dressing, toileting, eating, writing, etc., is obvious. But parents couldn't separate whether those benefits are of therapy itself or those are because the therapy environment is home.

\section{CONCLUSION}

The number of disabled people, including children, is rising all over the world (WHO, 2018) which is also true for Armenia. Lack of facilities for rehabilitation in Armenia leads to the development of in-home services in all related rehabilitation field professions.

Armenian parents, like all parents, want their children to have all possible opportunities for therapies as soon as the need is obvious, in-home services included. None of the parents wants to waste time on waiting lists of specialized service providers, so if they see a possibility to get services earlier, they take the opportunity. Moreover, parents like that situation of "open doors" to therapies, because it lets them see and somehow "monitor" the situation. The fact that they can talk to therapists before and/or after sessions as long and as detailed as they need, can't be overestimated. That serves to build rapport and mutually solve problems and challenges rising during the child's development. While reflecting children with special needs and their development, not in the general course, parents have a lot of questions and no professional counselor or service is often available with enough time to answer.

Convenience seems to be the basic reason for in-home treatments within this study. Based on that, we conclude that even after 12 years of existence, the awareness about Occupational Therapy in Armenia is very low. Yet that core imperatives of Occupational therapy of enablement of occupation in everyday contexts (Law, Baum \& Baptiste, 2002) is being practiced in Armenia too, but even related professionals couldn't explain to the parents the specificities of Occupational 
therapy. Parents grasp some notion about it during therapy time in several months within every time explanation from the therapist.

The limitation of this study includes the shortness of the number of participants which was connected to the number of current clients of the researcher. At the moment of the study, no other Occupational Therapist was providing only in-home pediatric Occupational Therapy services which also cut the possibility to recruit parents from other therapists.

Given the insights from this research, it is highly recommended for Occupational Therapy practitioners on different levels to expand information about the profession in general and unique traits in particular. That will help parents to understand issues and areas that are crucial for the Occupational Therapy. Therapists should spread information about the profession in all possible means in all related institutions using parents' language with parents and clinical language with professionals. Education can be a critical way in which parents are provided the knowledge to advocate for their children and help them reach their therapeutic goals. It is known that educated parents better help their children.

\section{REFERENCE LIST}

1. Adams, E. (2010). The joys and challenges of semi-structured interviewing. Community practitioner: The Journal of the Community Practitioners '\&Health Visitors' Association 2010; 83 (7), 18-21

2. Adams, W. (2015). Conducting semi-structured interviews, Handbook of Practical Program Evaluation, Fourth Edition, Jossey-Bass, Wiley Imprint

3. Ayres, A., J. (1979). In Stephenson, E., McKay, C., Chesson, R. (1990). An investigative study of early developmental factors in children with motor/learning difficulties. British Journal of Occupational Therapy, 53, 1, 4 - 6.

4. Braun, V., \& Clarke, B. (2006). Using thematic analysis in psychology. Qualitative research in Psychology, 3, 77-101.

5. Cohn, E., S. (2000). From Waiting to Relating: Parents' Experiences in the Waiting Room of an Occupational Therapy Clinic. The American Journal of Occupational Therapy, 55, 2, $167-174$ 
6. Cohn, E., Miller, L.J, \& Tickle-Degnen, L. (1999). Parental hopes for Therapy Outcomes: Children with Sensory Modulation Disorder. The American Journal of Occupational Therapy, 54, 1, 36-43

7. Daly, J., Kellehear, A., \& Gliksman, M. (1997). The public health researcher: A methodological approach. Melbourne, Australia: Oxford University press, 24-26.

8. Emerson, E. (2003). Effectiveness of Occupational Performance Coaching in Improving Children's and Mothers' Performance and Mothers' Self-Competence. The American Journal of Occupational Therapy,67, 1, 10-18

9. Farel, A.M., Meyer, R.E., Hicken, M., \& Edmonds, L.D., (2003). Registry to referral: using birth defects registries to refer infants and toddlers for early intervention services, Birth Defects Research (Part A). Clinical and Molecular teratology, 67, 647-650.

10. Gallimore, R. (1989). Cited in Cohn, E., Miller, L.J, Tickle-Degnen, L. (1999). Parental hopes for Therapy Outcomes: Children with Sensory Modulation Disorder. The American Journal of Occupational Therapy, 54, 1, 36-43

11. Graham, F., Rodger, S., \& Ziviani, J. (2013). Effectiveness of Occupational Performance Coaching in Improving Children's and Mothers' Performance and Mothers' SelfCompetence. The American Journal of Occupational Therapy, 67, 1, 10-18

12. Guralnick, M. (1997). Cited in Berlin, L.J., Brooks-Gunn, J., McCarton, C., Mc Cormick, M.C. (1998) The effectiveness of early intervention: examining risk factors and pathways to enhanced development. Preventative Medicine, 27, 238-245.

13. Hauser-Cram, P. (2001). Cited in Graham, F., Rodger, S., Ziviani, J. (2013) Effectiveness of Occupational Performance Coaching in Improving Children's and Mothers' Performance and Mothers' Self-Competence. The American Journal of Occupational Therapy,67, 1, 10-18

14. Hinojosa, J., Anderson, J., \& Strauch, C. (1988). Pediatric Occupational Therapy in the Home. The American Journal of Occupational Therapy,42, 1, 17-22

15. Hinojosa, J., Kramer, P., \& Royeen, C. (2017) Perspectives on Human Occupation: Theories Underlying Practice, Second Edition

16. Law, M., Baum, C.M., \& Baptiste, S. (2002). Occupation-based practice: Fostering performance and participation. Thorofare, NJ: Slack

17. Law of social protection of persons with disabilities of RA, 1993 
18. Lekskulchai, R., \& Col, J. (2001). Cited in Palisano R.J, Snider L.M, Orhi M.N (2004). Recent advances in physical \& occupational therapy for children with cerebral palsy. Seminars in Pediatric Neurology, 11, 1, 66-77.

19. MacKean, G.L., Thurston, W.E., \& Scott, C.M. (2005). Bridging the divide between families and health professionals' perspectives on family-centered care. Health Expectations, 8, 74-85.

20. Marquenie, K. (2011). Cited in Graham F, Rodger S, Ziviani J (2013). Effectiveness of Occupational Performance Coaching in Improving Children's and Mothers' Performance and Mothers' Self-Competence. The American Journal of Occupational Therapy,67, 1, 10 18

21. Nayar, S., \& Stanley, M. (2015). Qualitative Research Methodologies for Occupational Science and Therapy. Routledge, Taylor \&Francis Group

22. Pelchat, D., Lefebvre, H., Proulx, M., \& Reidy, M. (2004). Parental Satisfaction with an early family intervention program. Journal of Perinatal \& Neonatal Nursing, 18, 2, 128144.

23. Rice, P., \& Ezzy, D. (1999.) Qualitative research methods: A health focus. Melbourne, Australia: Oxford University Press.

24. ARMSTAT, Statistical Committee of the Republic of Armenia (2018), www.armstat.am

25. Stephens, L.C., \& Tauber, S.K. (2001). In Case-Smith J (2001). Occupational Therapy for Children. 4th edition, Mosby Inc, Elsevier Science, United States of America.

26. UNICEF, Mapping project Armenia 2017-2018, https://www.un.am/en/agency/UNICEF

27. Whiting, L. S. (2008). Semi-structured interviews: guidance for novice researchers. Nursing Standard, 22, 23, 35-40 